\title{
DA INTERPRETAÇÃO À CIÊNCIA: POR UMA HISTÓRIA FILOSÓFICA DO CONHECIMENTO POLÍTICO NO BRASIL*
}

Renato Lessa

Facts and illusion are equivalents...trying to weed one out in favor of the other is dealing with an incomplete situation. SANDBACK, 2011.

A partir da década de 1970, o Brasil, do ponto de vista dos que produzem, aprendem ou, simplesmente, consomem conhecimento político sistemático, deixou de ser interpretado e passou a ser explicado por enunciados com pretensão à demonstração. Entre a interpretação e a explicação, o passo almejado é gigantesco. Por certo, a legião de autores que, desde a implantação do Estado nacional brasileiro, nos idos de 1822 , buscou interpretar o que se passava no país, possuía pretensões à explicação, posto que não era constituída por nefelibatas puros. Da mesma forma, poderá ser dito que qualquer pretensão explicativa, por mais ingênua que possa ser a candura de sua autoapreciação, jamais fugirá dos limites e das possibilidades estabelecidos por modalidades de interpretação. A distinção, pois, entre interpretação e explicação é, no limite, insustentável em termos conceituais. Se

\footnotetext{
* Ensaio escrito durante minha estada como Investigador Visitante Sênior do Instituto de Filosofia da Linguagem da Universidade Nova de Lisboa. Agradeço a António Marques, seu diretor, a gentileza do convite, a enorme amabilidade do acolhimento e a oportunidade de me valer do ambiente intelectual da instituição. Utilizo, no ensaio, argumentos e formulações já desenvolvidas no texto "O campo da ciência política no Brasil: uma aproximação construtivista” (Lessa, 2010a).
} 
assim o é para o plano das definições categoriais, o mesmo não se dá no plano da afirmação de campos cognitivos.

Nessa medida, há uma demarcação clara entre o que hoje designamos como "intérpretes do Brasil" e o que, a partir da década de 1970, se definiu, entre nós, como o campo de uma ciência da política. Sob o rótulo genérico de "pensamento político brasileiro", um conjunto variado e expressivo de esforços cognitivos se transforma em objeto de história intelectual, enquanto que o corpo conceitual da nova ciência é tomado como condição para a inteligibilidade do mundo político.

No limite, não se trata mais de ler os "intérpretes do Brasil”, para neles buscar explicações a respeito do que é o país. Com frequência, o caminho é o inverso: são eles é que exigem o ser explicados, agora como objetos de uma história intelectual. Os "intérpretes" reemergem como assunto de história das ideias e não mais frequentam o núcleo da explicação a respeito do que é e deve ser o país.

Este ensaio parte de uma reflexão a respeito da passagem entre esses dois momentos do conhecimento político no país. Mais que simples sucessão de autores e teorias, sugiro a presença de uma transfiguração profunda no modo de falar a respeito dos fenômenos políticos. A direção assumida, a partir dos anos da década de 1970, foi a da afirmação de uma ciência positiva da política, depurada das confusões "normativas" do campo das humanidades e progressivamente afastada das demais ciências sociais, em nome da defesa de uma autonomia e de uma distinção de seu objeto.

O argumento, a ser desenvolvido, seguirá os seguintes passos:

(i) exame do calendário "oficial" de fixação da ciência política no Brasil, e as demarcações implicadas nessa fixação, com efeitos sobre a distinção entre "intérpretes do Brasil" e "cientistas", ou praticantes de um corpo de conhecimento cientificamente constituído; 
(ii) menção a alguns aspectos do mundo que antecedeu a afirmação da cultura científica, sobretudo na associação entre conhecimento e normatividade;

(iii) a busca de ideias autônomas e distintas, por parte da nova cultura científica, prescritas pela nova ciência da política;

(iv) um exame da experiência norte-americana, como fonte inspiradora para a reorientação do conhecimento político sistemático no Brasil;

(v) a decantação dos valores e dos procedimentos aprendidos com essa experiência, na configuração do campo no Brasil;

(vi) uma menção à nova cultura científica, sustentada no neoinstitucionalismo e na rational choice, a partir de fins da década de 1980, e suas principais implicações para a configuração do campo;

(vii) uma reflexão final sobre o tema da "transfiguração de objetos" e da centralidade dos "modos de falar" a respeito deles. Nessa conclusão, com base em argumentos estabelecidos por Willard Quine, Nelson Goodman e Arthur Danto, procurarei sugerir que novas modalidades de falar a respeito dos objetos podem operar com críticas fortes ao conhecimento político, tal como produzido pelo mainstream da ciência política.

\section{O nascimento de uma ciência da política: problemas de certificação e de constituição do campo}

Não há, ainda, uma história sistemática da ciência política brasileira, enquanto domínio reconhecido e institucionalizado. A disciplina é empreendimento de extração recente e, a depender do marco escolhido, não ultrapassa datação de quatro décadas de idade. Com efeito, os praticantes do campo, em ação no país e como corpo profissional cujos padrões disciplinares foram fixados e consolidados nos anos 1970-80, distribuem-se em não mais do que três ou quatro gerações. 
Trata-se, portanto, de uma trajetória ainda marcada pela perspectiva da curta duração e pela sombra dos "heróis fundadores". No entanto, a ideia de um começo recente não parece ser suficiente para dar suporte à crença de que se está diante de algo inaudito e cuja inauguração dispensa a consideração de antecedentes. Para os fins deste ensaio, duas ordens de antecedentes devem ser indicadas.

A primeira delas possui caráter negativo: na postulação de um novo começo, com que tradições se está a romper ou superar? O que teria existido antes desse suposto começo? Um vazio ou algo a ser superado, e cujos conteúdos, por alguma razão, foram julgados insuficientes de acordo com as razões dos que estabeleceram a ideia desse novo começo? Qual a medida dessa ruptura?

A segunda possui aspecto positivo: é que o tal começo decorre em grande medida de movimentos anteriores, ocorridos no campo do conhecimento político, durante a 20 década de 1950 nos Estados Unidos, em torno da assim chamada "revolução behaviorista". Essa, com certeza, decorre de movimentos anteriores, mas tal regressão ao infinito não será aqui reencenada.

O novo começo é pautado por atos paradigmáticos de recusa de uma tradição tida como ensaística e indisciplinada e de adesão a protocolos de explicação positiva dos fenômenos políticos. A centralidade dessa aposta realista é imensa e possui implicações sistêmicas sobre a configuração global da disciplina no Brasil.

O que se está aqui a dizer é que a "história curta" - e local - inscreve-se, de um modo que lhe é próprio, em uma "história mais larga", dotada de um conjunto de práticas e efeitos de conhecimento propiciados por uma disciplina cujos fundamentos e temas foram constituídos em outros domínios e outras temporalidades. Tal ato de constituição, por certo, exigiu uma demarcação crítica com relação a modalidades de representação do mundo político e social 
tidas como pré-científicas e progressivamente isoladas sob a denominação residual de "pensamento político brasileiro" ou, mais recentemente, "interpretações do Brasil”.

\section{Do mundo infinito à finitude do objeto encerrado}

O mais sistemático exercício de reflexão sobre a constituição da ciência política no Brasil foi elaborado, há cerca de trinta anos, por Bolívar Lamounier, em síntese do seminário "A ciência política nos anos 80", ocorrido em novembro de 1981, no então recém-fundado Instituto de Estudos Econômicos, Sociais e Políticos de São Paulo (Idesp). Os textos ali apresentados foram reunidos em excelente livro, com idêntico título, no ano seguinte (Lamounier, 1982). O texto fixou, ainda, a datação que acabou por se tornar uma referência identitária para a maioria dos cientistas políticos brasileiros, a saber, a que estabelece um espaço de tempo de quinze a vinte anos - entre meados da década de 1960 e o início da de 1980 -, como o período no qual a forma e a substância atuais da ciência política no Brasil se consolidam ${ }^{1}$.

Apesar de adotar e fixar essa datação, Lamounier reconhece, em uma perspectiva de largo prazo, a concomitância havida no Brasil entre os processos de fundação e constituição do Estado nacional, a partir do século XIX, e a emergência de uma reflexão sistemática e atenta à importância dos fatores de ordem política e institucional na configuração geral do país.

Mais do que justo o reconhecimento, pois nos primórdios do processo de configuração do Estado nacional brasileiro é já possível detectar os ecos de um intenso debate a

\footnotetext{
${ }^{1}$ Maria Cecilia Spina Forjaz adotará idêntica datação: "Irmã caçula das Ciências Sociais, a Ciência Política afirma sua identidade a partir de meados dos anos 1960, quando já se constituíra no país um sistema de ensino superior ao qual esteve estreitamente vinculado o desenvolvimento intelectual e institucional dessas disciplinas, especialmente no eixo São Paulo-Rio de Janeiro” (Forjaz, 1997).
} 
respeito do experimento social e institucional a ser desenvolvido no país. Trata-se, por certo, de uma reflexão - que no campo liberal radical, já nas primeiras décadas do século XIX, pode ser encontrada em gente como Cipriano Barata de Almeida, Frei Joaquim do Amor Divino Caneca, João Soares Lisboa e Gonçalves Ledo e no campo mais conservador em José da Silva Lisboa (Visconde de Cairu) e, mesmo, José Bonifácio - voltada para a intervenção direta na conjuntura imediata dos conturbados anos do processo de independência.

Nenhuma dessas intervenções preencheria, com certeza, os protocolos mais tarde fixados para configurar uma ciência supostamente rigorosa da política. No entanto, o propósito de intervenção imediata de modo algum apareceu, nos primeiros pensadores políticos do país, como algo paroquial e idiossincrático. Ao contrário, foi sempre visível a incorporação fertilizadora de tendências coetâneas no 22 campo da filosofia política, no plano internacional. As linguagens do liberalismo - em chave radical e democratizante ou em outra mais inclinada para os temas da liberdade de comércio - que comparecem ao primeiro grande debate público brasileiro, que culminou no processo de elaboração da primeira Constituição, outorgada em $1824^{2}$.

Mesmo nos limites de uma alusão rápida e superficial, é possível sustentar a presença de um pensamento político ativo, motivado não apenas por influências "estrangeiras" - francesas, inglesas e norte-americanas, sobretudo -, mas também pela oportunidade de intervir em um processo de criação de nova unidade política. Tal oportunidade foi de extrema valia para a fixação de uma tradição de pensamento político, a um só tempo voltada para o entendimento e a interpretação de problemas postos pela dinâmica polí-

\footnotetext{
${ }^{2}$ A propósito da intensidade do debate político e da presença de correntes liberais radicais e democratizantes, ver Leite (2000) e, para um comentário, Lessa (2010c).
} 
tica e social do país e para o desenho de configurações alternativas possíveis ${ }^{3}$. A precedência de um pensamento político, a um só tempo atento ao debate internacional e voltado para a intervenção prática, já naquela altura, deve deflacionar nossas sensações de que o campo de conhecimento supostamente estabelecido a partir da consolidação da moderna pós-graduação no país é contemporâneo de sua própria história ${ }^{4}$.

A avaliação de Lamounier (1982, p. 408) confere à ciência política no Brasil um patamar de "relativo avanço", propiciado por dois fatores, um de natureza histórica e outro de extração institucional, a saber:

(i) a "existência de uma importante tradição de pensamento político, anterior aos surtos de crescimento econômico e urbanização" do século XX e "mesmo ao estabelecimento das primeiras universidades";

(ii) a "expansão quantitativa da pós-graduação e a concomitante diversificação de formas institucionais que se operaram a partir meados dos anos sessenta”.

Ambos os fatores operam como cláusulas externas à constituição do campo. O primeiro dos fatores diz de uma pré-história do conhecimento político, na qual ter-se-ia estabelecido o hábito regular de pensar a vida pública. A afirmação da precedência, nos termos em que é feita, nada diz, em princípio, de continuidades analíticas e fertilizações substantivas. Apesar da precedência dessa pré-história, a nova ciência foi, em grande medida, feita contra ela. O segundo fator é abertamente institucional: são as condições

\footnotetext{
3 Três obras importantes, entre outras, podem dar ao leitor a medida da riqueza da reflexão política brasileira durante o Império: Carvalho $(1980,1988)$ e Mercadante (1965).

${ }^{4}$ É importante, aqui, mencionar o belo esforço intelectual, executado por Gildo Marçal Brandão, em seu incontornável livro Linhagens do pensamento político brasileiro (Brandão, 2007), no sentido de fixar as linhas de longa duração e de continuidade no âmbito do pensamento político brasileiro.
} 
"concretas" postas por um novo desenho das instituições universitárias no país que se oferecem como moldura para a configuração interna do campo.

Se esses são os fatores exteriores - um genético e outro institucional -, há que perguntar a respeito de marcadores mais precisos, a operar no interior do campo demarcado pela ruptura histórica e pela nova circunstância institucional. Encontramos no texto de Lamounier (1982, p. 408) tais marcadores mais finos:

(i) uma "autonomia bastante acentuada no que diz respeito à construção de seu objeto": tanto nos debates dos anos 1920-30 sobre a "organização política nacional", como nas teses e pesquisas contemporâneas, teria se configurado uma ciência política não subsumida em outros domínios analíticos, das humanidades e das ciências sociais;

(ii) um processo de distinção entre a ciência política e as demais disciplinas que compõem o campo das ciências 24 sociais, por meio de uma progressiva "profissionalização": trata-se da "diferenciação de um papel profissional e de instituições específicas, em relação às demais ciências sociais”.

O primeiro dos marcadores finos - a presença de uma acentuada "autonomia" a respeito da constituição do objeto - afirma a presença continuada de uma atenção a dimensões políticas e institucionais, como base de um exercício intelectual que toma a política como sua referência central. O segundo incide sobre o processo de demarcação desse saber científico da política com relação a outras disciplinas que configuram o campo mais amplo das ciências sociais e, é necessário frisar, das humanidades em geral. Ambos os marcadores são de consideração compulsória para que se compreenda a configuração mais geral do campo da ciência política. É o que será feito a seguir, sob os seguintes rótulos:

(i) o problema da autonomia e do embeddness e

(ii) o problema da demarcação e da distinção. 


\section{Autonomia e embeddness}

Manuel Villaverde Cabral, participante do seminário acima aludido, em ensaio a respeito da constituição da ciência política em Portugal, chamou a atenção para o fato de que em seu país uma reflexão sistemática, na qual a dimensão política compareça como aspecto central, só será praticada de modo continuado após a revolução democrática do 25 de abril de 1974 (Cabral, 1982; Matos, 1982). Até então, a reflexão política portuguesa, quando não asfixiada e dirigida pelo experimento do salazarismo, aparecia imersa no que Villaverde Cabral designou como um "ciclo de embeddment", pelo qual a narrativa política sempre acabava encerrada - embebida, envolvida ou enraizada - em "casulos" estabelecidos pela narrativa histórica mítica e remota. A imagem é excelente e presta-se a desenvolver o tema do processo de autonomização do campo, na definição de seus objetos próprios.

É a ideia de embeddness, originalmente aplicada por Karl Polanyi para descrever a relação entre circuitos de troca econômica e vida social, em um mundo ainda intocado pelo "credo de mercado", que aqui emerge como marcador da posição ocupada pela reflexão política, diante de outras modalidades narrativas a respeito da experiência social ${ }^{5}$. Polanyi, de forma lapidar, mostrou como as relações econômicas estiveram, antes do predomínio do credo na excelência do mercado autorregulado, envolvidas - embedded - em um conjunto de injunções não econômicas. Tal padrão de embeddness sustentava-se em formas institucionais e normativas que acabaram por configurar o modo de lidar com questões econômicas. O próprio modo de tratar e narrar fenômenos econômicos implicava a consideração de fatores posteriormente tidos como não econômicos, associados, de modo lato, à tradição e ao âmbito mais amplo das crenças e da cultura.

\footnotetext{
5 Para a ideia de embeddness, ver Polanyi (1978).
} 
É possível sustentar que todo processo de autonomização resulta de uma recusa a padrões de embeddness. $\mathrm{O}$ segmento a ser autonomizado deve ser apresentado como dotado de qualidades ontológicas próprias, que justificam o destaque com relação a conjuntos que, até então, determinavam seu sentido e seu alcance. O contrário também pode ser afirmado: a recusa de padrões de autonomia implica a adesão a vínculos mais totalizadores, sem os quais o sentido do fragmento esmaece.

A aplicação do ponto ao tema do conhecimento político manifesta-se na oposição entre narrativas que compreendem os fenômenos políticos como inseridos em redes de causalidades mais amplas - históricas, culturais, sociais, ecológicas etc. - e narrativas que os encerram em circuitos restritos e autônomos com relação ao que se considera como não dotado de relevância propriamente política.

Pode-se dizer que o termo "autonomia", tal como intro26 duzido por Lamounier, designa a relativa ausência dos efeitos de embeddness, responsáveis pela dissipação da sensibilidade analítica com vistas a fenômenos políticos. Os assim chamados fatores estritamente políticos apareceriam - ou teriam sido constituídos, para utilizar terminologia filosoficamente menos ingênua - de modo não encerrado ou embebido em narrativas de outras ordens, que os vinculariam a dinâmicas não estritamente políticas. No que toca à reflexão brasileira, a visibilidade e a relevância descontaminadas de temas de natureza política teria sido marcante, desde seus primórdios. O efeito diacrônico presente nesse juízo, no entanto, é menos uma homenagem à tradição do que um recurso a ela dirigido para sustentar um argumento a respeito de como devem ser o presente e o futuro do campo que se está a afirmar: um campo que não fará concessões ao "historicismo", ao "culturalismo" e ao "sociologismo".

Tal suposição de pregnância entre a disciplina e o seu objeto estrito, por outro lado, traz consigo a ideia de que a 
constituição do campo exige procedimentos de transfiguração, pelos quais efeitos de descontaminação e depuração são exercidos. A crença implícita é a de que existe correlação positiva entre "desencasulamento", isolamento analítico de fragmentos, cada vez menores, e progresso cognitivo. Em outros termos, a autonomia significa que os fenômenos observados devem ser retirados de "casulos" e percebidos no que revelam de intrinsecamente políticos. A questão toda é a de que não há como estabelecer propriedades intrínsecas de qualquer conjunto a não ser pela operação de critérios extrínsecos de primeira ordem.

Há mais, no entanto, a ser explorado com relação ao tema do embeddness, a partir do texto de Manuel Villaverde Cabral. De modo mais direto, é necessário distinguir dois padrões distintos de embeddness. Uma coisa é dizer de uma dissolução - ou apagamento - da sensibilidade analítica para fenômenos políticos por força das artes de um regime hiperautoritário, que impõe e fixa como narrativa compulsória a respeito da experiência nacional uma forma retórica mítica e hagiográfica. Outra, e muito distinta, diz respeito à presença de uma atenção analítica efetiva a temas políticos, porém atada a hábitos intelectuais segundo os quais as narrativas que disso decorrem não exigem desvincular-se de outras modalidades de expressão.

Tal distinção parece-me crucial para entender o próprio processo brasileiro de afirmação de um pensamento político. Se for verdade que, desde os primórdios, uma atenção ao caráter distintivo da política se fez presente, por outro, é importante considerar que o tratamento intelectual de temas políticos não implicou, no contexto dessa origem, na constituição de um saber específico e autárquico da política.

Ao contrário, a tradição do ensaísmo brasileiro, fortíssima até os anos 1960, e ainda não de todo extinta, ao considerar temas de natureza política, o fez de um modo tal 
que narrativas históricas, literárias, filosóficas, sociológicas, econômicas e de outras extrações comparecessem à análise. "Autonomia", nesse caso, implicava apenas o reconhecimento de um domínio de objetos a considerar, mas não a adesão a um saber distinto e independente das demais narrativas sobre a experiência histórica, cultural e social. Se a primeira forma de autonomia é uma condição necessária para que falemos de política, a segunda é mais discutível.

\section{Os princípios da demarcação e da distinção}

Campos de conhecimento não se fazem apenas a partir de petições de autonomia, fundadas no caráter supostamente estrito de seus objetos pretendidos e prediletos. Tal movimento é necessário, mas não esgota em si mesmo os efeitos produzidos pela sua afirmação. Ele produz, de modo igualmente compulsório, deslocamentos, novas afinidades e novos estranhamentos. Desde já, deve ser dito que o proces28 so de afirmação de uma ciência política soi disant autônoma no Brasil fez-se acompanhar de duplo processo de ruptura:

(i) com o campo e com as linguagens das humanidades, como efeito da ruptura empreendida por sua principal fonte inspiradora e constituinte - a revolução behaviorista dos anos 1950 nos EUA; e

(ii) com o campo das ciências sociais, a partir do predomínio da linguagem e dos temas do neoinstitucionalismo e da rational choice, a partir de fins dos anos 1980.

A dupla demarcação possui consequências não triviais, pois o que está em jogo é a própria pertença desse campo cognitivo - a ciência política - com relação ao âmbito mais largo das ciências sociais e das humanidades.

O princípio da autonomia, presente ainda no marcador "profissionalização", destacado por Bolívar Lamounier, indica o passo subsequente ao reconhecimento originário de um domínio propriamente político e discreto de objetos, na direção da afirmação de uma profissão espe- 
cífica - na verdade, uma "comunidade epistêmica" particular, para adotar os termos de Haas (1992) -, dotada de identidade, recursos cognitivos, hábitos institucionais e linguagens próprias e compartilhadas e formas de expressão e presença públicas.

Narrativas a respeito do campo são formas de constituição desse mesmo campo. Neste sentido, o texto seminal de Bolívar Lamounier, formulado em contexto no qual os efeitos do neoinstitucionalismo e da ideologia da rational choice na constituição da ciência política brasileira ainda não se tinham feito presentes - é bom que fique isso claro - é um momento preciso e particular de constituição do próprio campo. Os movimentos fundamentais da narrativa opõem a detecção de um período longo - que vai dos primórdios do pensamento político brasileiro até os anos 1960 - a outro, mais recente e configurado por alterações de corte institucional.

No primeiro caso, encontramos intelectuais isolados, a praticar um ensaísmo histórico-sociológico aberto, sem sinais de adensamento e apuro disciplinar. Na outra ponta, a indicar desdobramentos recentes, uma expansão forte de programas de pós-graduação e uma diversificação de formas institucionais de trabalho: departamentos universitários e centros de pesquisa, públicos e privados. Nessa segunda fase, o exercício de reflexão a respeito da política teria ganhado contornos de maior continuidade e sistematicidade, em um processo concomitante ao da progressiva profissionalização dos produtores de conhecimento político.

\section{Um vago olhar sobre o mundo que antecede a autonomia e a distinção}

O longo período que antecedeu à moderna institucionalização da ciência política - e das ciências sociais em geral - carrega certo signo de negatividade. O período teria sido povoado por pensadores que trabalharam, por vezes, de 
modo isolado e diletante, sem o lastro institucional das universidades e centros de pesquisa. Esforços mais recentes, e outros nem tanto, no campo da história do pensamento político brasileiro, têm procurado demonstrar a consistência dessas tradições e suas formas próprias de fixação ${ }^{6}$.

O tema da formação do Estado e da nação teria sido, ainda de acordo com o enquadramento proposto por Lamounier em seu valioso texto-síntese, o marco de referência inicial para um pensamento sistemático sobre a política. Com efeito, é possível encontrar os termos de uma rica agenda política e intelectual, já na reflexão do século XIX, em torno de temas nada triviais ou amadorísticos: centralização ou descentralização política, prerrogativas do Poder Moderador, reforma eleitoral, abolição, propriedade fundiária, papel das forças armadas e forma de governo, entre outros.

Tal agenda e tal variedade de enquadramento viriam 30 a ser recepcionadas durante a Primeira República, tendo como "forma narrativa específica [...], o ensaio histórico, a grande reflexão sobre a história nacional"(Lamounier, 1982, p. 411). Tal forma reuniu, nas primeiras décadas do regime republicano, intelectuais tais como Euclides da Cunha, Sylvio Romero, Ruy Barbosa, Alberto Torres e Oliveira Vianna. A esse grupo somar-se-iam, ainda, Azevedo Amaral, Francisco Campos e Nestor Duarte. Do mesmo modo, a linhagem intelectual que conectou gente como Alberto Torres, Oliveira Vianna, Francisco Campos e Azevedo Amaral produziu forte impacto na agenda política e institucional do país, a partir dos anos 1930.

Tal conjunto heteróclito compartilhou de algumas características comuns, ressaltadas na análise de Lamounier, a saber:

${ }^{6}$ É o caso do já mencionado Linhagens do pensamento político brasileiro. Cabe a referência, ainda, a Santos (1967) e Lamounier (1977). 
(i) A prática de "um trabalho essencialmente individual, sem apoio universitário e sem crítica acadêmica sistemática";

(ii) uma inserção imediata da "luta ideológica", em um padrão distinto do da cultura acadêmica, marcada pela "análise diferenciada das premissas e/ou da investigação empírica, vistos como contribuições a uma literatura profissional cumulativa";

(iii) produção de um diagnóstico convergente, segundo o qual o país era dotado de elites com caráter clânico e fortemente associadas à propriedade da terra, a impedir uma "diferenciação da esfera pública" e a constituir-se em grave óbice para a consolidação do Estado;

(iv) percepção das "massas" como imersas na pobreza, na dispersão e na inorganicidade, vitimadas por uma "massificação pré-capitalista";

(v) percepção de que a viabilidade do Estado não poderá depender das vias históricas "normais", de fundo societário, já que ele deve se constituir como antídoto à fatalidade sociológica do atraso, fundado na estrutura clânica e em complexos culturais arcaicos (Lamounier, 1982, p. 413).

O conjunto, assim configurado, apresenta forte aproximação entre "disposição analítica" e "projeção normativa". Trata-se, afinal, de entender os aspectos básicos do travamento da afirmação do Estado nacional e de, ao mesmo tempo, indicar alternativas de intervenção e de fabricação institucional. A esfera política - quando não a da própria ação política - é apresentada como referência estratégica para a modernização do país, a despeito do caráter regressivo e inercial das instituições sociais. Em termos mais diretos, tem-se aqui uma perspectiva segundo a qual as alterações sociais podem ser pensadas como efeitos do redesenho institucional e estatal. A demiurgia estatal aparece, portanto, como operador necessário da projeção normativa acima aludida. 
O clássico livro de Vitor Nunes Leal, Coronelismo, enxada e voto, publicado em 1948, representou uma inflexão importante com relação à tradição acima indicada. Nunes Leal, por certo, herdou de seus predecessores a preocupação com os fatores de atraso social do país e com suas implicações para a configuração de um espaço público. De modo mais preciso, procurou enfrentar um dilema central para o regime constitucional inaugurado em 1946, o primeiro experimento brasileiro de política mais aberta e competitiva e no qual o voto passa a cumprir papel relevante. A análise de Nunes Leal, embora focada em aspectos de organização política e administrativa, não se apresentava como centrada exclusivamente em fatores políticos. Para ele, a modernização social do país traria consigo a redução do peso específico dos complexos arcaicos enfatizados na obra de Oliveira Vianna. Não se trata mais de pensar a constituição de uma esfera pública como contraponto à inércia social, mas de buscar uma asso32 ciação entre mudança social e democratização política. Os aspectos de natureza política e institucional aparecem, pois, no livro de Nunes Leal como imersos - para trazer de volta o tema da embeddness - em um conjunto de injunções históricas e sociológicas. Será essa a marca das principais obras de reflexão política produzidas no país, até os idos de 1964.

Com efeito, algumas das principais obras produzidas entre fins dos anos 1940 e o início da década de 1960 a respeito dos dilemas e das perspectivas do país, ainda que apresentem forte preocupação com questões de natureza política, podem melhor ser percebidas como "interpretações do Brasil”. Uma seleção, não exaustiva, além do livro de Nunes Leal, poderia indicar como representativos os seguintes autores e obras: Oliveira Vianna (1949), Guerreiro Ramos (1961), Pinto (1956, 1960) e Faoro (1958). Não é o caso aqui de esmiuçar suas teses, mas de indicar que, a despeito da enorme diversidade de suas abordagens e orientações, as obras e os autores mencionados configuram 
um campo de reflexão no qual o tema específico da política encontra-se vinculado a um vasto conjunto de questões e referências mais amplas.

Tal conjunto opõe-se, a um só tempo, às cláusulas da autonomia/embeddness e da distinção progressiva, na medida em que associa de modo explícito análise e prescrição e persegue a ideia de que a inteligibilidade da política deve ser buscada nos nexos que mantém com a história, com a vida social e, o que é mais importante, com o que se quer do futuro. Se algo há em comum entre os autores acima mencionados, como representativos da reflexão política e social brasileira entre os anos 1940 e 1960, é seu caráter indisfarçavelmente normativo.

Consulte-se, por exemplo, o belo ensaio do filósofo Álvaro Vieira Pinto, a respeito da ideologia do desenvolvimento nacional lido pelo autor em aula inaugural do Instituto Superior de Estudos Brasileiros (Iseb), no qual os ouvintes são instados a adotar a "perspectiva do infinito" e a perceber o desenvolvimento como um imperativo para a democratização fundamental do país (Pinto, 1956). Em chave mais depressiva, a análise de Faoro, publicada em 1958, projeta sobre a história do país a sombra de um legado patrimonialista, cujos contornos, do que resultar de um esforço descritivo, derivam de uma concepção fortemente normativa a respeito do processo histórico brasileiro ${ }^{7}$.

Os dois exemplos, creio, são suficientes para indicar a presença de uma forte perspectiva de envolvimento da observação política com outras tradições reflexivas - filosofia e história -, assim como a força de uma motivação normativa. É como se o esclarecimento do que se apresenta como sendo o caso exigisse como complemento a indicação de como as coisas devem ser.

\footnotetext{
${ }^{7}$ Esse livro de Faoro viria a ter impacto tardio na reflexão brasileira, sobretudo a partir de sua reedição ampliada no início dos anos 1970. Para uma recepção importante e pioneira das teses de Faoro, ver Schwartzman (1975).
} 
Como se pode depreender, essa tradição analítica e normativa difere em muitas de suas características daquilo que viria a ser considerado, a partir dos anos 1970, como um produto paradigmático da ciência política. Os marcadores da profissionalização far-se-ão mais salientes e a recusa progressiva de envolvimento com narrativas históricas, sociológicas e culturalistas se afirmará como cláusula pétrea. Não sem surpresa, o padrão tradicional de associação entre análise e prescrição estará, a partir de 1964, progressivamente sob crítica cerrada. Resta saber que novo padrão de prescrição viria a ocupar o espaço deixado pelo anterior. Somos todos adultos, e não nos é dado imaginar que em algum momento prescrições deixaram de ser feitas.

\section{A busca de ideias autônomas e distintas}

As transformações ocorridas na dinâmica política e social brasileira no pós-1964 afetaram profundamente a substân34 cia e as formas de organização das ciências sociais no país ${ }^{8}$. Para além dos impactos regressivos e repressivos, o novo "regime" reestruturou progressivamente o ambiente institucional da ciência brasileira. O próprio sistema nacional de pós-graduação, implantado pela reforma universitária de 1968, como notou Maria Cecília Spina Forjaz, em sua avaliação sobre a ciência política brasileira,

ampliou enormemente o mercado de docentes universitários, pesquisadores, bolsas de estudo, bibliotecas, laboratórios e todos os outros aparatos necessários ao desenvolvimento científico num leque bastante diversificado de áreas de conhecimento, expansão com a qual as Ciências Sociais em geral, e a Ciência Política em particular, também foram beneficiadas.

${ }^{8}$ Para uma compreensão mais apurada desse processo, ver Miceli (1989). 
A disposição de constituir um ambiente institucional favorável à atividade científica, em contexto autoritário, aparece à primeira vista como paradoxal, dada a associação habitual entre ânimo repressivo e obscurantismo científico e cultural. É à natureza modernizadora do regime de 1964 que deve ser debitada tal configuração aparentemente esdrúxula, e não a seus traços autoritários. Em outros termos, a correlação hipotética defensável parece ser a que associa "progresso científico" à "modernização" e não a autoritarismo. É de se crer que qualquer regime, desde que composto por uma perspectiva "modernizadora", teria como atributo necessário uma agenda positiva de política científica.

De modo mais preciso, o que viria a ser designado como a "institucionalização da ciência política" esteve fortemente vinculado ao desenho e a montagem desse sistema de pós-graduação. Além de alterações institucionais imediatas, no campo da vida universitária e da ciência, os novos tempos caracterizar-se-iam pela afirmação progressiva do papel do Estado na configuração da sociedade brasileira.

Se os temas do desenvolvimento, da questão nacional e das reformas de base, na primeira metade dos anos 1960, constituíram-se como atratores quase compulsórios para a reflexão política, o quadro a partir dos idos de março de 1964 será um tanto distinto. A partir da segunda metade da década de 1960, o macrotema que se impõe, a interpelar a capacidade analítica dos cientistas sociais, é o da crescente presença e preeminência do Estado em praticamente todos os processos sociais.

Não é que o tema "Estado" estivesse ausente na reflexão anterior a 1964. A diferença no pós-1964 é a de que ele passa a ser considerado menos como um domínio fixado na dinâmica social mais ampla, e resultante de processos históricos de longo prazo, e passa a ser percebido como arena autárquica na qual múltiplos processos decisórios têm lugar. O deslocamento teve, por certo, precedentes na 
ciência política norte-americana, na qual a ideia de Estado, julgada metafísica e sociologicamente contaminada, cede lugar a "governo", a "administração" ou ao "sistema político". Falar-se-á cada vez menos em "Estado" e cada vez mais em "processos decisórios” e em "políticas públicas”, expressões acrescentadas nos anos 1970 ao vocabulário político brasileiro, com presença ubíqua no vocabulário dos agentes políticos e sociais, fora do âmbito acadêmico.

Para além das alterações ocorridas na agenda de política científica e na própria configuração do espaço público, há que acrescentar o fenômeno da socialização de uma importante geração de cientistas sociais - a variante política aí incluída - nos temas e nos padrões disciplinares da ciência política norte-americana, a partir de fins da década de 1960 e na seguinte. Vários dos aspectos ressaltados como constitutivos da identidade da disciplina a partir da década de 1970 estão associados a esse nexo, em particu36 lar o da profissionalização e o da postulação ontológica de um âmbito da política autônomo com relação a outras dinâmicas sociais.

\section{América}

O contato com a ciência política norte-americana - tomado, por vezes, como sinônimo de "internacionalização" encontrou naquele país uma disciplina dotada de uma história própria. O passado então recente daquela disciplina - a partir de meados dos anos 1940 - fora atravessado por uma mutação intelectual com impactos sobre o conjunto das ciências sociais e das humanidades nos Estados Unidos.

É importante ter, ainda que de forma muito breve, uma ideia da densidade histórica da disciplina em seu contexto norte-americano, já que ela está fixada como influência estruturante na trajetória originária daquilo que viria a ser a ciência política brasileira, a partir dos anos 1960. Para tal, valer-me-ei de alguns resultados de um importante projeto, 
desenvolvido nos Estados Unidos em meados da década de 1990, a respeito do estado das ciências sociais e humanas, tal como praticadas naquele país, nos cinquenta anos que a antecederam.

Em meados dos anos 1990, dois dos mais prestigiosos historiadores norte-americanos - Thomas Bender e Carl Schorske - foram responsáveis pela edição de um balanço crítico a respeito das ciências sociais e humanas nos Estados Unidos $^{9}$. Trata-se de um excelente e ainda vívido quadro histórico de parte das ciências sociais e das humanidades naquele país. Ali aparecem dilemas e contornos internos, assim como vinculações com o ambiente cultural, político e social mais amplo. A menção, ainda que breve, a alguns aspectos revelados pelo projeto desenvolvido por Bender e Schorske pode ser útil para algum entendimento de dinâmicas presentes no campo da ciência política no Brasil.

\section{Virada asséptica e horror à ideologia}

O projeto concentrou-se em quatro campos disciplinares: economia, filosofia, estudos de inglês e ciência política. Para cada um deles eminentes praticantes foram convocados a contribuir com textos que mesclaram memorialismo e análise. Na apresentação do livro, Bender e Schorske mencionam a ocorrência de uma "virtual refundação" das quatro disciplinas, na virada das décadas de 1940 e 1950 (Bender e Schorske, 1998, p. 6). Tal refundação teria sido motivada pelo desejo de superar o que então se percebia como o legado ideológico da década de 1930, cujos ecos podem ser encontrados em dois documentos importantes para a história da educação superior norte-americana: "General education in a free society", elaborado em 1945 por uma

\footnotetext{
${ }^{9}$ O projeto - designado como "American academic culture in transformation" -, abrigado pela American Academy of Arts and Sciences, resultou, em primeiro lugar, em número especial da revista Daedalus, em 1997. Foi, a seguir, transformado em livro, publicado pela Universidade de Princeton: Bender e Schorske (1998).
} 
comissão da Universidade de Harvard - mais conhecido como o "Red book" - e "Higher education for democracy", vasto relatório publicado em 1947 pela Comissão de Educação Superior (Comission on Higher Education). Ambos os documentos afirmam a importância do desenvolvimento da cultura científica e da tradição humanística europeia e uma ideia de formação intelectual associada a responsabilidades de direção dos assuntos públicos (Bender, 1998, p. 20) ${ }^{10}$.

Com a virada, ocorrida ao fim dos anos 1940 e durante a década seguinte, marcadores internalistas passam a ter primazia como aferidores de excelência, em detrimento de outros, de natureza externalista, mais atentos ao vínculo da academia com o espaço cívico e público. Difunde-se um padrão de excelência definido em termos cada vez mais endógenos. Richard Freeland, em importante livro, chamou a atenção para uma alteração no padrão de constituency da academia: não mais o âmbito público em geral, mas os 38 próprios âmbitos disciplinares e as formas institucionais que os sustentam ${ }^{11}$. O mesmo processo foi percebido e analisado por David Riesman e Christopher Jencks, ao qual atribuíram o termo "revolução acadêmica” (Jenkins e Riesman, 1968). Dois valores podem ser apresentados como síntese dessas mutações: autonomia acadêmica e profissionalismo disciplinar. Como se pode ver, tais tendências não foram inventadas ao sul da linha do equador. Bender indica, ainda, as implicações desses valores para a organização das ciências sociais e humanas (Bender, 1998, p. 20):

\footnotetext{
${ }^{10}$ De acordo com o "Red book", toda prioridade deveria ser conferida a investigar e ensinar "o lugar das aspirações e ideais humanos no esquema geral de todas as coisas". Todo o debate a respeito da direção a ser seguida pela "higher education" norte-americana, com ênfase nas humanidades, pode ser encontrado no excelente livro de Hofstadter e Smith (1961).

${ }^{11}$ É esse o sentido do comentário geral de Freeland a respeito da mutação ocorrida a partir dos anos 1940, que aqui reproduzo: "os constituencies centrais da cultura acadêmica foram as disciplinas acadêmicas e sociedades científicas que a patrocionaram, pois foram esses grupos que puderam conferir a ela uma reputação de excelência” (Freeland, 1992).
} 
(i) devoção ao modelo das hard sciences;

(ii) compromisso com a objetividade;

(iii) confiança no poder da análise formal;

(iv) aversão à ideologia e a ameaças à "pureza disciplinar”.

O trabalho acadêmico adquire, portanto, uma perspectiva internalista (inward-looking) e devota-se primariamente ao desenvolvimento disciplinar e treinamento dos estudantes para a disciplina em questão.

Dificilmente poderíamos encontrar uma evidência tão forte da presença de tal reorientação no campo das ciências sociais quanto a fornecida em discurso proferido por Talcott Parsons, em 1959, na reunião da American Sociological Association. Segundo Parsons, como disciplina científica, a sociologia dedica-se primária e claramente ao avanço à transmissão de conhecimento empírico e apenas secundariamente à comunicação de tal conhecimento a não praticantes da disciplina (apud Bender, 1998, p. 22) ${ }^{12}$. Parsons opõe-se, assim, de modo aberto a concepções segundo as quais o avanço da disciplina tem como principal motivo a comunicação a não praticantes e a usuários - governos, associações e o público em geral ${ }^{13}$.

A virada, contida na ideia de uma "revolução acadêmica”, apresentou-se de forma diferenciada, mas eloquente, nas quatro disciplinas analisadas pelo empreendimento coordenado por Bender e Schorske. A economia, a partir dos anos 1940, vê-se tomada pelo progressivo abandono dos temas keynesianos clássicos - inscritos em uma perspectiva de economia política e, mesmo, social - e passa a afirmar-se como econometria e a adotar uma linguagem formalizada

\footnotetext{
${ }^{12}$ Interessante notar, em chave contrastiva, o que pensava Mário de Andrade: a sociologia é a "arte de salvar rapidamente o Brasil" (Andrade, 1972, p. 41).

${ }^{13}$ No debate contemporâneo no campo da sociologia, essa última versão vem sendo defendida pelo sociólogo Michael Burawoy, em torno da ideia de uma "sociologia pública” (Burawoy, 2005). Ver ainda, para uma reação no campo da sociologia brasileira, Simon Schwartzman (2009).
} 
e não natural ${ }^{14}$. Os estudos de inglês, sob a égide do New Criticism, passam a ser atravessados por uma cultura intelectual formalista, que virá a ser contestada, nos anos 1960, pela emergência dos Estudos Culturais (Cultural Studies) - e pelo desenvolvimento de perspectivas fundadas em questões de gênero e pertencimento étnico (Abrams, 1998; Gallagher, 1998). No campo da filosofia, a reorientação manifestar-se-ia pelo predomíno avassalador da filosofia analítica, em detrimento da ênfase clássica em temas de natureza ética e normativa, associados a investigações sobre a própria história do pensamento filosófico (Putnam, 1998; Nehamas, 1998). No domínio da ciência política, a virada tomou a forma do que foi designado como uma "revolução behaviorista".

Um tanto triunfalista, a expressão "revolução behaviorista" designa uma reorientação ocorrida no campo do conhecimento político, a partir dos anos 1950. A virada pretendia afirmar tal conhecimento como uma "ciência", com 40 protocolos distintos dos praticados pela filosofia política, percebida como contaminada por fortes componentes historicistas e normativos. A reorientação proposta pretendia, ainda, executar uma virada empírica e positiva no campo do conhecimento da vida política, voltada para a explicação de como os fenômenos políticos ocorrem no assim chamado mundo real. Uma ciência da política, assim revolucionada, deveria sustentar-se em bases exclusivamente realistas e experimentais e dispensar referências de ordem normativa.

Os adeptos da revolução dirigiram pesadas críticas à tradição da filosofia política - ou da teoria política. Segundo eles, esse campo teria esgotado sua capacidade de inovação intelectual e, dessa forma, refluído para um mero esforço historiográfico a respeito de si mesma (Easton, 1953, 1966, 1969). É como se, por falta de assunto, tivesse passado a tra-

\footnotetext{
${ }^{14}$ Três excelentes ensaios são devotados às mutações na disciplina de economia: Solow (1998), Kreps (1998) e Barber (1998).
} 
tar de sua própria história como objeto privilegiado e perdido a capacidade de dizer coisas a respeito do mundo realmente existente. Por essa via, a teoria política, para Easton, teria perdido sua vocação original de formular "ideias a respeito de questões públicas" e de estabelecer um "quadro moral de referência” (Easton, 1953, p. 234). Tal vocação teria desaparecido por força de um decline into historicism, por meio do qual a teoria política acaba por confundir-se com o campo da história das ideias políticas.

A defesa de uma ciência descontaminada das querelas ideológicas e apegada a procedimentos de descrição rigorosos mal podia camuflar seus pressupostos normativos. Os termos de Easton eram claros: trata-se de desenvolver uma ciência capaz de estabelecer um novo quadro de referência. Tal quadro, para os autores envolvidos no "movimento", era constituído por valores e práticas afirmadas como "democráticas" e inscritas na tradição política e institucional norte-americana. Ciência cum democracia, esta última definida nos termos de um modelo civilizatório na altura ameaçado por alternativas então apresentadas como “totalitárias”. Trata-se de uma associação que se quer necessária.

Há que acrescentar, contudo, o terceiro termo: ciência, democracia e Guerra Fria. O próprio Easton dirá, em texto publicado em 1991, que o macartismo representou um estímulo para o desenvolvimento de uma ciência política mais objetiva e científica, na medida em que ao proporcionar uma "postura de proteção para os acadêmicos", de não envolvimento político e ideológico, teria resultado em algum ganho para a disciplina, mesmo se "pelas razões erradas" (Easton, 1991, p. 44).

Não se insinua, aqui, a presença de uma necessária adesão aos "valores" e à cultura paranoica do macartismo, por parte dos cientistas políticos behavioristas. A correlação a ser feita é a que se estabelece entre a crença na necessidade de uma ciência descontaminada de seu passado ideológico 
e o desenvolvimento de uma cultura intelectual de insulamento, ainda que comprometida com o fato da democracia, como objeto e como âncora cívica. Charles Lindblom, em ensaio inspirado, chamou a atenção para o conflito constitutivo presente nessa versão cientificista do conhecimento político: ao mesmo tempo em que cultua valores epistemológicos assépticos, afirma seu compromisso com a democracia (Lindblom, 1998).

Não é de surpreender, portanto, que o tratamento da democracia venha a ser apresentado como subordinado a "teorias descritivas" e não a concepções "maximizadoras", tal como posto em um dos textos mais importantes e inspirados da ciência política nos anos $1950^{15}$. Ainda assim, o apego à democracia, como objeto e como ideal, ainda que deflacionado, opera como cláusula normativa evidente, já que qualquer seleção de objetos relevantes, no campo do conhecimento político, dependerá do desenho normativo 42 de ordem com o qual se trabalha ${ }^{16}$.

Para além de seus resíduos normativos, o behaviorismo não reinou de forma exclusiva e absoluta. Até certo ponto constitui uma caricatura supor que o "movimento" tenha sido capaz de organizar e subordinar todo o campo cognitivo devotado de modo sistemático a questões de natureza pública. O próprio Easton registrou, em meados da década de 1980, os fatores que, a seu juízo, estiveram presentes em uma virada pós-behaviorista, já nos anos 1960: o movimento pelos direitos civis, pelos direitos da população negra e de outras "minorias", protestos contra a guerra do Vietnã e, em termos mais amplos, o que designou como a "revolução da contracultura" (Easton, 1985, p. 141). Outro impor-

\footnotetext{
${ }^{15}$ Refiro-me ao incontornável Dahl (1956).

${ }^{16}$ Para uma consideração dos pressupostos normativos da ciência eastoniana ver Strong (1998). Os limites e as implicações da perspectiva behaviorista foram tratados no artigo seminal de Wolin (1969). Igualmente importante é o ensaio de Almond (1990).
} 
tante cientista político, também envolvido com movimento behaviorista - Charles Lindblom - destacou, além do desafio provocado pelos aspectos mencionados por Easton, a presença do que designou como um "Pollyannaism", caracterizado pela produção de "interpretações benignas" do sistema político norte-americano. Pace Lindblom, tais interpretações prendiam-se a aspectos funcionais e internos dos "sistemas" - e o próprio termo "sistema" é o operador por excelência dessa perspectiva -, ignorando questões tais como a exclusão racial e desigualdade social (Schorske, 1998, p. 318).

\section{Brasil, depois da América}

\section{Das prescrições}

Os efeitos no Brasil da cultura científica estabelecida pela virada behaviorista foram, por certo, muito fortes. Ao contrário de narrativas, típicas do universo mental anterior a 1964, nas quais a política era percebida como efeito de dinâmicas sociais e históricas mais amplas, a nova cultura científica tenderá a pôr em relevo a autonomia dos fenômenos políticos e institucionais. Vale dizer, a sua capacidade de constituírem-se em certo sentido como causas de si mesmos e a exigir aproximações analíticas de corte internalista.

Algumas das teses de doutorado, produzidas por cientistas políticos e sociais brasileiros, já expostos ao clima intelectual acima mencionado, ilustram o ponto. Wanderley Guilherme dos Santos, por exemplo, em sua tese elaborada em Stanford (Santos, 1979), procurou demonstrar como o padrão interno de interações no Legislativo brasileiro marcado segundo o autor pela presença de uma "paralisia decisória” -, durante o governo de João Goulart, foi um fator decisivo na crise de 1964 (Santos, 2003). Olavo Brasil de Lima Jr., em tese elaborada em Michigan e defendida em 1980, construiu uma engenhosa interpretação do siste- 
ma partidário brasileiro, entre 1945 e 1964, com base em fatores estritamente internalistas: dimensões institucionais e legais, racionalidade política das alianças eleitorais, sistema de representação e o papel dos "subsistemas" partidários (Lima Jr., 1983).

Entre os vários traços decorrentes da cultura científica estabelecida pela "revolução behaviorista", há que destacar a presença de forte preocupação com relação a aspectos definidos como "metodológicos", com imensa ênfase quantitativa. O termo "treinamento" passou a fazer parte do jargão constitutivo dos praticantes da disciplina. Mais do que isso, afirma-se uma dimensão "metodológica", com foros de independência com relação a temas substantivo a ser tratados e ao campo filosófico da teoria do conhecimento $^{17}$. Vem, certamente, dessa demarcação, o caráter afilosófico da formação dos novos praticantes do novo campo. Tais marcas identitárias serão indicadoras de 44 uma funda diferença com relação à cultura ensaística dos "intérpretes do Brasil”, negativamente afetados pelo juízo de obsolescência agregada do Brasil pré-1964, adotadas como crença profissional básica da nova ciência da política em território nacional.

Ao par da virada metodológica, aprofunda-se o tema da autonomização da política. A ênfase marxista na precedência do "econômico" - e, por extensão, do social - aparece como índice de grave reducionismo e hiperdeterminismo. Ainda que haja bons argumentos para sustentar a crítica, o abandono de hipóteses marxistas acabou por gerar uma desconsideração geral a respeito de qualquer perspectiva fundada em narrativas históricas e sociais, como cruciais para a inteligibilidade da política. O declínio e o desprestígio da sociologia política entre nós, assim o indicam.

\footnotetext{
${ }^{17}$ Para uma reflexão crítica a respeito da obsessão metodológica, ver o ainda seminal artigo Wolin (1969).
} 
O próprio vínculo com a economia, como dimensão estruturante da política, é redefinido: não se trata mais uma dimensão de contexto mais amplo que impacta a dinâmica da política, mas sim, e a um só tempo, uma antropologia e uma linguagem. A primeira revela as motivações reais dos sujeitos sociais, definidos como "máquina global de maximização”, para aqui empregar a fórmula feliz de Elster (1984, p. 10). A segunda - a linguagem - permite que se descreva tal sujeito tal como é, sem metafísica ou projeção na direção do que ele não é. A nova incursão da economia como inspiração para o entendimento da política afirma-se por meio de circularidade invencível: suas explicações são verdadeiras, na medida em que os agentes sociais se comportam de acordo com os fundamentos das explicações. Tal percepção da política foi difundida, a partir dos anos da década de 1970, a partir de autores e textos tais como Downs (1957), Riker (1962) e Olson Jr. (1965).

\section{0 que a vida fez com as prescrições}

O rebatimento da experiência norte-americana sobre o espaço brasileiro trouxe bem mais do que simples replicação. A própria difusão da literatura sistêmica e behaviorista, de modo não infrequente, foi acompanhada da introdução de alguns de seus antídotos. Isso talvez se deva ao fato de que a exposição aos temas do behaviorismo, por parte da geração que "fez a América”, tenha se dado nos quadros do que poderia ser designado como um "behaviorismo tardio”, em uma altura na qual pressupostos do movimento, vigoroso durante a década de 1950, encontravam-se largamente atacados.

O fato é que parte expressiva da geração de estudantes de pós-graduação em ciência política, no Brasil de fins da década de 1970, ao mesmo tempo em que era apresentada ao cânone, tinha acesso à crítica radical que a acusava como marcada por uma desatenção ao caráter excludente 
da definição da agenda pública e aos processos de geração permanente de "não decisões"18. Incorporava-se certo ethos cientificista, mas ao mesmo tempo praticava-se a crítica de uma "política apolítica"19, esvaziada de conteúdos normativos, ao defenderem a retomada - ou simplesmente a continuidade - de um programa de reflexão no qual os fundamentos normativos da ordem política sejam considerados (ver Wolin, 1960).

Uma cultura científica curiosa parece ter emergido e se difundido. Ao mesmo tempo em que desenvolve e consolida um senso interno de identidade profissional e de trabalho acadêmico, com a afirmação da pesquisa no âmbito da universidade e em alguns centros isolados, o campo do conhecimento político sistemático apresenta forte diversidade, do ponto de vista de suas linguagens e ênfases. Temas fortes da tradição da filosofia política, por exemplo, nunca desapareceram.

A despeito de crenças idiossincráticas de exclusividade e de precedência, hoje correntes, o campo que se constitui já a partir dos anos 1960 é marcado por consistente pluralidade. Parte não desprezível dessa pluralidade pode ser debitada ao envolvimento de parte significativa dos praticantes do campo com questões de natureza política, na qualidade de cidadãos e militantes. Até meados da década de 1980, o envolvimento dos politólogos - e dos cientistas sociais em geral - com questões de natureza pública não era infrequente. A persona compósita do cientista/militante impediu o estranhamento completo com relação à tradição dos "intérpretes do Brasil". Vários dos protagonistas dessa tradição caracterizaram-se, tal como fartamente sabido, pela associação entre busca de esclarecimento analítico e histórico com forte envolvimento com a vida pública.

\footnotetext{
${ }^{18}$ Ver o artigo clássico Bachrach e Baratz (1962). Na mesma chave inscreve-se Bachrach (1966).

${ }^{19}$ A expressão aparece em McCoy e Playford (1967).
} 
Uma segunda onda de envolvimento com tais questões configurar-se-á a partir da década de 1990, tendo como protagonista o politólogo técnico - tanto no mundo da opinião como no da consultoria profissional -, do qual se espera a formulação de juízos explicativos, supostamente depurados de contaminação normativa. Essa nova identidade não deixará de exercer demandas precisas a respeito do padrão de ensino e de pesquisa a ser adotado pelos centros de investigação em ciência política. Tais demandas - e as respostas que as retroalimentam - têm valido como fatores de aceleração e aprofundamento dos já mencionados processos de autonomização e distinção.

Mas, se pensarmos, ainda, no contexto dos anos da década de 1980, vale o juízo de que certo ethos de militância - política, cívica ou social - se inscrevia no horizonte existencial de parte expressiva dos praticantes do campo. Há que considerar, ainda, outro aspecto que viria a ter forte impacto sobre o rebatimento no Brasil de uma cultura científica positiva e empiricamente orientada.

No modelo original disseminado pela experiência norte-americana, a ideia de uma ciência política empírica para descrever a democracia assenta-se sobre uma fusão entre horizontes factuais e normativos. Em termos diretos, tratava-se de estudar - e promover - a democracia como objeto realmente existente, e não como fabulação doutrinária. No rebatimento dessa tradição no Brasil, a nova ciência, configurada em não pequena medida pelos valores de uma ciência positiva e empírica, acabou por investigar não a democracia, mas o "autoritarismo" e, por essa via, a vislumbrar formas de superação.

Para dizê-lo de modo claro, uma "teoria empírica da democracia" acabou por exigir uma "teoria empírica da ausência de democracia". É evidente que tal passagem se deu por meio de operadores de ordem normativa, a valorizar de modo positivo a democracia, ainda que a descrevessem mais 
como conjunto de procedimentos do que como materialização de valores e crenças e como experimento fundado em requisitos de reconfiguração social.

\section{Prescrições revisitadas: uma nova cultura do conhecimento político científico}

Uma nova cultura científica se constitui no campo do conhecimento político, no Brasil, a partir da década de 1990. Como toda novidade, foi antecedida por episódios intelectuais propiciadores, já aqui referidos e associados à cultura científica da "revolução behaviorista". Nessa reafirmação de valores já estabelecidos, trata-se de aprofundar os processos de autonomização dos objetos e de distinção com relação a domínios cognitivos pertencentes aos campos das ciências sociais e das humanidades.

A atenção aos processos de democratização, e seus requisitos, dá progressivamente passagem para a análise das 48 instituições, percebidas como de consideração compulsória para avaliar o modus operandi da própria democracia. $\mathrm{O}$ tema genérico das transições para a democracia, que exigia atenção a sequências históricas, assim como a fatores sociais e culturais, dá lugar à inspeção de como operam, em oceano calmo, as chamadas instituições da democracia. A rotinização política do país do ponto de vista institucional dá, assim, azo a uma sensibilidade analítica atenta aos fatores de permanência. A democracia, julgada "consolidada", converte-se em um fato, mais do que em propósito ou valor. De uma vaga crença na democracia como valor universal, parte-se agora da sua afirmação como fato universalizável. Tal universalização possível dependerá, para já, do desenho correto de instituições e de práticas institucionais. O tema da accountability, por exemplo, ganha foros de horizonte normativo máximo. Assim como nas firmas, o desempenho dos governantes passa a ser avaliado em função de sua capacidade e competência da prestação de contas. 
No domínio das ciências sociais, a ciência política adquire fisionomia crescentemente mais conservadora. Ciência das instituições e de seu funcionamento, mais do que de sua transformação e de sua historicidade, e com dificuldades analíticas crescentes para dizer algo de significativo a respeito do mundo extrainstitucional. Há como o quê a presença do que poderia ser designado como um "oficialismo ontológico". Se Hegel, em certa altura, disse que "todo o real é racional”, o politólogo "médio", egresso dessa nova cultura científica, aprenderá que todo real é institucional - ou oficial. O próprio registro do que significam as instituições é restrito e se confunde com o mundo oficial, por meio de um raciocínio abertamente circular: as instituições são o institucional.

$\mathrm{O}$ afastamento com relação à linguagem e aos temas das ciências sociais e das humanidades, contudo, não configura uma processo genérico e indistinto de autonomização disciplinar. A recusa dessa tradição é acompanhada da afirmação de novas alianças. Em outros termos, a desinscrição do domínio das ciências sociais pode ser percebida como o lado simétrico da inscrição em outros campos. A ruptura com as humanidades e com a tradição das ciências sociais correu ao par de uma aproximação com linguagens formais e não naturais e com axiomas da microeconomia. É o que permite representar sujeitos sociais como "eleitores" e portadores de "preferências", e instituições como "incentivos”. Se comunidades epistêmicas são reconhecíveis pela linguagem particular que empregam, o emprego de tais termos pode ser assumido como índice da presença de politólogos no mundo.

Tomar tal linguagem como descrição natural da política é atribuir à forma de vida que a inventou - uma forma de vida constituída pelo utilitarismo e pela generalização social das relações de mercado - a prerrogativa de revelar os que os sujeitos humanos são em si mesmos. É evidente 
que tal suposição não pode ser seriamente formulada em um debate rigoroso no campo da teoria do conhecimento. Ela vale o que vale, isto é como crença privada - e ideologia compartilhada - de seus praticantes.

Sob o rótulo do neoinstitucionalismo diferentes formas de representação da vida política podem ser constituídas. Em artigo publicado em 1996, Peter Hall e Rosemary Taylor procuram esclarecer as diferenças entre três modalidades possíveis e propõem um protocolo de cooperação entre elas (Hall e Taylor, 1996). As três variantes do neoinstitucionalismo seriam as seguintes: histórica, sociológica e fundada na escolha racional. As duas primeiras, a despeito de diferenças de configuração interna, praticam modalidades de externalismo na interpretação das instituições. Quer isso dizer que dinâmicas mais gerais - de natureza histórica e sociológica - são julgadas cruciais para a gênese das instituições. Essas, por sua vez, são percebidas como dotadas da 50 capacidade de afetar a configuração de tais dinâmicas mais gerais. Não se trata de reencenar os limites de um determinismo estrutural ou de uma fatalidade histórica, como precipitações inelutáveis sobre a trama da política, mas de buscar a elucidação de um nexo fundamental: em que medida instituições - e a própria ação política - afetam e são afetadas por condições mais amplas e intertemporais?

A variante neoinstitucionalista, fundada na ideologia da escolha racional, é a que mais radicaliza as prescrições originais, afirmadas na virada científica dos anos 1950. A inspiração behaviorista mais ampla ganha aqui mais nitidez e, sobretudo, capacidade de formalização, com a adoção de linguagens formais e não naturais.

Mas, antes de tudo, a variante está assentada em uma antropologia segundo a qual os sujeitos humanos são, ainda nos termos postos por Elster, máquinas globais de maximização. As implicações para o tratamento do tema das instituições são diretas: os indivíduos aderem a pautas insti- 
tucionais - isto é, a modelos de comportamento - porque perderiam mais se não o fizessem. É evidente que isso equivale a dizer que aderem porque ganham mais do que se não aderirem ${ }^{20}$. Ambos os juízos são, além de equivalentes, fundados em afirmações ex post facto e, no limite, aplicáveis a qualquer decisão humana. São nesse sentido infalsificáveis e tautológicos ${ }^{21}$.

Há nessa circularidade a afirmação ideológica de um atributo, apresentado como universal e intertemporal, qual seja, o da presença de uma disposição utilitarista na constituição da condição humana. Os efeitos exercidos pela história e pela cultura incidem sobre um animal que, mais do que pertencente ao gênero homo sapiens, melhor poderia ser apresentado como homo choicer. Apesar de sua pretensão à centralidade, essa visão de mundo não opera no vazio. Não apenas há outras modalidades de representação da vida política e social, o que é trivial, mas há, sobretudo, um conjunto robusto de refutações à tal pretensão de universalidade. A começar pelo jovem Marx, ao apresentar a pretensão da teoria econômica de seu tempo em definir a natureza humana como um "efeito particular de uma forma social específica e historicamente fundada”. Em outros termos, "a pretensão à universalidade só se torna inteligível como manifestação de uma posição particular”, um juízo já classicamente posto pela tradição do ceticismo filosófico.

Por "posição particular" deve-se entender não apenas modalidades de descrição do mundo, mas suportes normativos que as orientam. O neoinstitucionalismo, em sua

\footnotetext{
${ }^{20}$ Uma forma deflacionada e, se calhar, mais genuína de estabelecer o ponto pode ser expressa do seguinte modo: os seres humanos, em geral, agem em função do que lhes parece ser mais adequado fazer em cada caso. É evidente que a generalidade da proposição coincide com um juízo tautológico. Qualquer ação humana pode ser descrita nesses termos. Sua aplicação a eventos contingentes, portanto, só poderá ter efeitos de reiteração e de certificação de racionalidade. ${ }^{21}$ Uma avaliação crítica, corajosa e fundamentada do paradigma da escolha racional pode ser encontrada em Carvalho (2009).
} 
variante rational choicer, adota como fundamento normativo de suas descrições os princípios valorativos gravitacionais de uma dada forma social, fundada na presunção de universalidade dos princípios do mercado autorregulado. Sua pretensão analítica, portanto, é mitigada pelo serviço que presta à perenidade dessa configuração social.

\section{Nota final}

O conhecimento político parece padecer de uma armadilha nominalista. Por ter o nome de seu objeto, a política - como disciplina e hábito de investigação - confunde-se com a "política", enquanto domínio ontológico. A crença na existência em objetos natural e eminentemente políticos impõe aos praticantes do campo uma cultura um tanto mimética e desatenta ao que não aparece como tal. Antropólogos e sociólogos, por sua vez, caracterizam-se mais por adotar uma perspectiva de análise das coisas do que da captu52 ra de fragmentos da ontologia do social, que pertencer-lhes-ia segundo direitos consuetudinários disciplinares. Nesse sentido, puderam desenvolver culturas disciplinares mais ágeis e diversificadas, sem respeitar fronteiras rigidamente demarcadas de objetos permitidos e interditos.

Tal aparente desvantagem do conhecimento político a política como nome de um campo que se ocupa de questões de natureza pública - pode ser compensada por fatores de outra ordem. Pode ser que o campo seja cativo de questões e províncias específicas da vida social. No entanto, as linguagens que empregamos para configurá-los como objetos de conhecimento possuem indisfarçável sabor normativo. O conhecimento político, afinal, é contemporâneo e conatural da "política" como atividade humana prática e reflexiva. Sua datação, nesse sentido, é quase imemorial. No tratamento de seus objetos, tal reflexão sempre foi obrigada a considerar questões de fato - organizadas em torno da questão "o que fazer?" - e questões normativas - "por que 
e para que fazer?". Nesse sentido, sempre incorporou uma dimensão alucinatória em suas representações do mundo. A própria ideia de decisão política, aparentemente técnica e asséptica, implica a crença de que os seus efeitos acrescentarão ao mundo algo que naturalmente ele não contém (ver Lessa, 2007, 2010b).

Em registro mais anedótico e pessoal, não conheço antropólogo envolvido na reforma de sistemas de parentesco ou mesmo sociólogo devotado a desenhar um sistema alternativo de estratificação social, como, por exemplo, adotar o modelo de castas. Os cientistas políticos, ao contrário, possuem modelos preferenciais de sistemas eleitorais, formas de governo e desenho das instituições. Talvez seja esse um traço constitutivo de uma tradição de reflexão sobre a vida pública, já anunciado por Aristóteles: a política é um saber prático, e não uma ciência teórica e devotada à contemplação de um mundo imóvel e eterno. Está, nesse sentido, associada à ação e à presença dos humanos na vida social e a seus esforços de imaginação e de entendimento.

A relativa fixidez de objetos é, portanto, compensada pela presença de esforços de prescrição. Todos prescrevem: prescrevem os que abertamente prescrevem e fazem-no os que se recusam a prescrever e aferram-se à forma presente das coisas. Isso faz com que os objetos sejam relevantes, pelo que supostamente são e pelo que não são, ou podem ser.

O filósofo Willard Quine, de certa feita, declarou: "somos todos propensos a falar de objetos" (Quine, 1975). Em outros termos, somos todos propensos a incluir algo que designamos por "fatos", ou "objetos", em nossas práticas linguísticas ou, se quisermos, jogos de linguagem. Com efeito, somos todos propensos a falar, e, na verdade, só podemos falar de objetos, não nos sendo dada outra alternativa existencial e ordinariamente consistente. Mesmo linguagens privadas e não naturais são obrigadas a falar de seus objetos. $\mathrm{O}$ modo da referencialidade - inscrito na suposição de que ao 
falarmos referimo-nos a algo - impõe-se, portanto, a todas as formas de falar.

Para retomar o argumento de Quine: a depender do termo a enfatizar - "falar" ou "objetos" -, o sentido da proposição "somos propensos a falar de objetos" dará passagem a narrativas distintas a respeito de nossos esforços cognitivos. Campos disciplinares, por exemplo, poderão ser apresentados tanto como circunscrições de objetos - com ênfase no termo "objeto" - quanto como formas de falar a respeito de objetos - com ênfase no termo "falar".

Com efeito, são nossos modos de falar que acabam por constituir os próprios objetos como temas dignos de nossa atenção. Campos de conhecimento estabelecem, portanto, condições de existência de objetos - i.e., suas características distintivas e os padrões de causalidade que os envolvem e seus marcadores de relevância, além dos procedimentos adequados de investigação e de validação. A inteligibilidade 54 desse complexo cognitivo não pode nos ser dada por algo assemelhado a uma inspeção direta dos objetos sobre os quais tais campos exercem seu domínio disciplinar. A razão é simples: não há objetos a investigar, fora de campos disciplinares que os definem enquanto tais.

A formulação filosófica direta e rigorosa do problema, no quadro da filosofia contemporânea, foi estabelecida por Nelson Goodman: descrições de mundo fazem sentido nos quadros de referência nos quais estão fundadas (Goodman, 1995, p. 3). Tal inscrição, mais do que um protocolo de nomeação de objetos, instaura regimes cognitivos, crenças causais e formas de correspondência e adequação - ou não - entre linguagem e mundo. Este é o sentido da orientação construtivista da abordagem de Goodman, presente em sua ideia seminal de que somos "praticantes de maneiras de criar mundos".

Não há aqui qualquer dualismo entre pensamento e extensão, já que não se trata de opor um mundo mental - 
abstrato e desenraizado - a um mundo fenomênico e material. Ambas as dimensões - a, digamos, "mental" e a que corresponde à extensão - encontram-se na linguagem, o modo humano de inscrição da referencialidade. Nesse sentido, nosso encontro com os objetos é um experimento que nos constitui enquanto sujeitos e que se realiza na linguagem que empregamos para falar deles, por meio de nossos protocolos disciplinares de classificação e interpretação. Uma sensibilidade - mais do que uma abordagem - construtivista a respeito do processo de formação de campos disciplinares inclina-se, portanto, para a apreensão dos quadros de referência em que tal experiência se faz possível.

Não se trata, portanto, de recusar a "vocação empírica" da ciência política, em nome de um tratamento pretensamente filosófico. Em imensa medida, não pode haver ciência - ou conhecimento, simplesmente - da política que não seja em alguma medida empírico. O problema - todo o problema, na verdade - reside no estatuto da experiência que temos com objetos. Tal estatuto não é proveniente dos objetos, mas dos regimes disciplinares e linguísticos que empregamos para falar a respeito deles. Não há, portanto, contrato epistemológico e linguístico férreo a determinar o que deve ser dito a respeito dos objetos que "realmente contam". $\mathrm{Na}$ descrição dos objetos, contam mais as formas de descrição do que os objetos propriamente ditos. Esses podem ser constantemente transfigurados em outras modalidades de descrição.

O filósofo Arthur Danto, em outro domínio, utilizou o termo "transfiguração" para designar o processo pelo qual objetos da nossa experiência ordinária - lugares comuns, tais como latas de sopa, urinóis e aros de bicicleta - são percebidos e compreendidos como inscritos no campo da arte (Danto, 2006). Assim, entre a arte de Marcel Duchamp ou Andy Warhol, por um lado, e aros de bicicleta e latas de sopa ordinários, operaria uma forma de distinção que procede por meio de uma transfiguração dos lugares comuns. 
Ainda que algumas formas da arte contemporânea em particular as inúmeras versões da arte ready made - procurem eliminar a distinção entre objetos de arte e, digamos, objetos da vida, distinções permanecem e estabelecem de modo claro aquilo sobre o qual nosso juízo estético deve ou não incidir. Em outros termos, a experiência estética que temos com as latas de Andy Warhol ou a roda de bicicleta ou o urinol de Marcel Duchamp resulta da operação de uma transfiguração de lugares comuns. Por meio de tal transfiguração, tais objetos podem ser percebidos como obras de arte. Claro está que o circuito da transfiguração exige nossa adesão como espectadores. Uma adesão que só se torna possível porque, de nossa parte, fomos constituídos como sujeitos habituados a certas formas de transfiguração. Em outros termos, aprendemos, desde muito cedo, a lidar com objetos e a distingui-los segundo modalidades consagradas de classificação.

A reflexão política - coetânea da política enquanto atividade humana - pode ser percebida como conjunto aberto de transfigurações. A definição dos objetos de uma ciência da política - qualquer que seja ela - só se torna inteligível se exibidos os fundamentos da transfiguração que a constitui. A linguagem do neoinstitucionalismo e da rational choice é tão somente uma das modalidades possíveis de determinação do que são os fatos. Seus recursos não devem ser subestimados: ela alimenta-se dos princípios gravitacionais da forma civilizatória presente. Mas, se a vocação da filosofia política, desde seus primórdios, sempre foi a de lidar com o que não existe, há espaço, tempo e, no que me diz respeito, disposição para praticar novas formas de transfiguração. Nesse sentido, a reaproximação com as humanidades e com as ciências sociais pode ser uma bela alternativa para que continuemos a dar curso a algo indelevelmente humano: falar, de objetos. 


\section{Renato Lessa}

é professor titular do Departamento de Ciência Política da UFF e investigador associado do Instituto de Ciências Sociais da Universidade Nova de Lisboa.

\section{Referências bibliográficas}

ABRAMS, M. 1998. "The transformation of English studies”. In: BENDER, T.; SCHORSKE, C. (orgs.). American academic culture in transformation: fifty years, four disciplines. Princeton: Princeton University Press.

ALMOND, G. 1990. "Clouds, clocks, and the study of politics". In: A discipline divided: schools and sects in political science. Newbury Park: Sage.

ANDRADE, M. 1972. O empalhador de passarinho. São Paulo: Martins Fontes. BACHRACH, P. 1966. The theory of democratic elitism. Boston: Little Brown. ; BARATZ, M. 1962. "Two faces of power". American Political Science Review, vol. 56, no 4, pp. 947-952.

BARBER, W. J. 1998. "Reconfiguration in American academic economics: a general practicioner's perspective”. In: BENDER, T.; SCHORSKE, C. E. (orgs.). American academic culture in transformation: fifty years, four disciplines. Princeton: Princeton University Press.

BENDER, T. 1998. "Politics, intellect, and the American university, 19451995”. In: BENDER, T.; SCHORSKE, C. E. (orgs.). American academic culture in transformation: fifty years, four disciplines. Princeton: Princeton University Press.

; SCHORSKE, C. E. 1998. American academic culture in transformation: fifty years, four disciplines. Princeton: Princeton University Press.

BRANDÃO, G. M. 2007. Linhagens do pensamento político brasileiro. São Paulo: Hucitec.

BURAWOY, M. 2005. "For public sociology". American Sociological Review, vol. $70, \mathrm{n}^{\circ}$ 1, pp. 4-25.

CABRAL, M. V. 1982. "História e política nas ciências sociais portuguesas, 1880-1980”. In: LAMOUNIER, B. (org.). A ciência política nos anos 80. Brasília: Ed. UnB.

CARVALHO, B. S. 2009. A escolha racional como teoria social e politica: uma interpretação crítica. Rio de Janeiro: Topbooks.

CARVALHO, J. M. 1980. A construção da ordem: a elite política imperial. Rio de Janeiro: Campus.

. 1988. Teatro de sombras: a política imperial. São Paulo: Vértice.

DAHL, R. 1956. Preface to democratic theory. Chicago: University of Chicago Press. 
DANTO, A. 2006. A transfiguração do lugar-comum. São Paulo: Cosac \& Naify. DOWNS, A. 1957. An economic theory of democracy. Nova York: Harper \& Row.

EASTON, D. 1953. The political system: an inquiry in the state of political science. Chicago: University of Chicago Press.

. 1966. A framework for political analysis. Englewood Cliffs: Prentice Hall.

. 1969. "The new revolution in political science". American Political Science Review, vol. 63, pp. 1051-1061.

. 1985. "Political science in the United States: past and present".

International Political Science Review, vol. 6, no 1, pp. 133-152.

. 1991. "Political science in the United States: past and present".

In: EASTON, D.; SCHELLING, C. (orgs.). Divided knowledge: across disciplines, across cultures. Newbury Park: Sage, 1991.

ELSTER, E. 1984. Ulysses and the sirens: rationality and irrationality. Cambridge: Cambridge University Press.

FAORO, R.. 1958. Os donos do poder: formação do patronato político brasileiro. Rio de Janeiro/Porto Alegre/São Paulo: Globo.

FREELAND, R. 1992. Academia's golden age: universities in Massachusetts, 1945-1970. Nova York: Oxford University Press.

58 GALLAGHER, C. 1998. "The history of literary criticism". In: BENDER, T.; SCHORSKE, C. E. (orgs.). American academic culture in transformation: fifty years, four disciplines. Princeton: Princeton University Press.

GOODMAN, N. 1995. Modos de fazer mundos. Porto: Edições ASA.

GUERREIRO RAMOS, A. A crise do poder no Brasil: problemas da revolução nacional brasileira. Rio de Janeiro: Jorge Zahar, 1961.

HAAS, P. M. 1992. "Knowledge, power, and international policy coordination: epistemic communities and international policy coordination”. International organization, vol. 46, nº 1, pp. 1-35.

HALL, P.; TAYLOR, R. 1996. "Political science and the three neo-institutionalisms”. Political Studies, vol. 64, no 44, pp. 936-957.

HOFSTADTER, R.; SMITH, W. 1961. American higher education: a documentary history. Chicago: University of Chicago Press.

JENKINS, C.; RIESMAN, D. 1968. The academic revolution. Nova York: Doubleday.

KREPS, D. 1998. "Economics: the current position". In: BENDER, T.; SCHORSKE, C. E. (orgs.). American academic culture in transformation: fifty years, four disciplines. Princeton: Princeton University Press.

LAMOUNIER, B. 1977. "Formação de um pensamento político autoritário na Primeira República: uma interpretação”. In: FAUSTO, B. (org.). 
História geral da civilização brasileira: o Brasil republicano. São Paulo: Difel (vol. 2).

. 1982. "A ciência política no Brasil: roteiro para um balanço crítico". In: (org.). A ciência política nos anos 80. Brasília: Ed. UnB.

LEAL, V. N. 1948. Coronelismo, enxada e voto. Rio de Janeiro: Forense.

LEITE, R. L. 2000. Republicanos e libertários: pensadores radicais no Rio de Janeiro (1822). Rio de Janeiro: Civilização Brasileira.

LESSA, R. 2007. "Política: anamnese, amnésia, transfigurações". In: NOVAES, A. (org.). O esquecimento da política. Rio de Janeiro: Agir. . 2010a. "O campo da ciência política no Brasil: uma aproximação construtivista”. In: (org.). Horizontes das ciências sociais no Brasil: ciência política. São Paulo: Discurso Editorial/Barcarolla.

. 2010b. "Da filosofia política e da crença (ou do que é necessário para a experiência do pensamento sobre a política)”. In: NOVAES, A. (org.). Mutações: a experiência do pensamento. São Paulo: Sesc.

LIMA JR., O. B. 1983. Partidos políticos brasileiros, de 45 a 64. Rio de Janeiro: Graal.

LINDBLOM, C. 1998. "Political science in the 1940s and 1960s". In: BENDER, T.; SCHORSKE, C. E. (orgs.). American academic culture in transformation: fifty years, four disciplines. Princeton: Princeton University Press.

MCCOY, C.; PLAYFORD, J. 1967. A political politics: a critique of behavioralism. Nova York: Thomas Crowell.

MATOS, L. S. 1982. "Generalidade e drama: pensamento político português, 1945-1980”. In: LAMOUNIER, B. (org.). A ciência política nos anos 80. Brasília: Ed. UnB.

MERCADANTE, P. 1965. A consciência conservadora no Brasil. Rio de Janeiro: Saga.

MICELI, S. (org.). 1989. História das ciências sociais no Brasil. São Paulo: Idesp/Vértice.

NEHAMAS, A. 1998. "Trends in recent American philosophy". In: BENDER, T.; SCHORSKE, C. E. (orgs.). American academic culture in transformation: fifty years, four disciplines. Princeton: Princeton University Press.

OLIVEIRA VIANNA, F. J. 1949. Instituições politicas brasileiras. Rio de Janeiro: José Olympio.

OLSON JR., M. L. 1965. The logic of collective action: public goods and the theory of groups. Cambridge: Harvard University Press.

PINTO, A. V. 1956. Ideologia e desenvolvimento nacional. Rio de Janeiro: Iseb. . 1960. Consciência e realidade nacional. Rio de Janeiro: Iseb.

POLANYI, K. 1978. A grande transformação. Rio de Janeiro: Campus. 
PUTNAM, H. 1998. "A half century of philosophy, viewed from within". In: BENDER, T.; SCHORSKE, C. E. (orgs.). American academic culture in transformation: fifty years, four disciplines. Princeton: Princeton University Press.

QUINE, W. O. 1975. "Relatividade ontológica e outros ensaios”. In: PORCHAT, O. (org.). Ensaios: Ryle, Austin, Quine, Strawson. São Paulo: Abril Cultural, 1975 (Coleção "Os Pensadores”).

RIKER, W. H. 1962. The theory of political coalitions. New Haven: Yale University Press.

SANTOS, W. G. 1967. “A imaginação político-social brasileira”. Dados, no 2-3, pp. 182-193.

. 1979. The calculus of conflict: impasse in Brazilian politics and crisis of 1964. Tese de doutoramento. Palo Alto: Stanford University.

. 2003. O cálculo do conflito: estabilidade e crise na política brasileira. Belo Horizonte: Ed. UFMG.

SCHORSKE, C. E. 1998. "The new rigorism in the human sciences". In: BENDER, T.; SCHORSKE, C. E. (orgs.). American academic culture in transformation: fifty years, four disciplines. Princeton: Princeton University Press. SCHWARTZMAN, S. 1975. São Paulo e o Estado nacional. São Paulo: Difel. 2009. “A sociologia como função pública no Brasil”. Caderno CRH, vol. 25, no 56, pp. 271-279.

SOLOW, R. 1998. "How did economics get that way and what way did it get”. In: BENDER, T.; SCHORSKE, C. E. (orgs.). American academic culture in transformation: fifty years, four disciplines. Princeton: Princeton University Press.

STRONG, T. 1998. "David Easton: reflections on an American scholar". Political Theory, vol. 26, nº 3, pp. 267-280.

WOLIN, S. Politics and vision: continuity and innovation in Western political thought. Boston: Little Brown.

1969. "Political theory as a vocation". American Political Science Review, vol. 63, nำ 4, pp. 1062-1082.

\section{Outros materiais}

FORJAZ, M. C. S. 1997. "A emergência da ciência política no Brasil: aspectos institucionais”. Revista Brasileira de Ciências Sociais, vol. 12, no 35. Disponível em: <http://www.anpocs.org.br/portal/publicacoes/rbcs_00_35/rbcs35_06.htm>. Acesso em 20/01/2011.

LESSA, R. 2010c. "A primeira esquerda brasileira”. Disponível em: <http://renatolessa-nonada.blogspot.com/2010/07/primeira-esquerda-brasileira.html>. Acesso em 20/02/2011.

SANDBACK, F. 2011. Catálogo de exposição no Museu Dia: Beacon. Beacon. 


\section{DA INTERPRETAÇÃO À CIÊNCIA: POR UMA HISTÓRIA FILOSÓFICA DO CONHECIMENTO POLÍTICO NO BRASIL}

\section{RENATO LESSA}

O ensaio trata da distinção presente, no campo da reflexão política brasileira, entre um registro apresentado como científico e outro fundado na interpretação. Tal distinção acaba por retirar da variante interpretativa - designada ora como "pensamento político brasileiro", ora como "interpretações do Brasil" - a possibilidade de gerar efeitos de conhecimento, transformando os autores que a compõem mais em objetos a explicar do que em inspirações propriamente cognitivas. Por outro lado, a pretensão de conhecimento exato e objetivo, abraçada pela variante "científica”, a partir dos anos 1980, pretende livrá-la dos limites inerentes ao exercício da interpretação. Tal processo tem por fio condutor uma progressiva transfiguração do objeto e do campo do conhecimento político, apresentado pela variante científica como marcado por forte especificidade. Uma especificidade que exigiria um continuado esforço de distinção com relação à tradição das humanidades e das ciências sociais.

Palavras-chave: Transfiguração; Autonomia; Distinção; Ciência política; Interpretações do Brasil.

\section{FROM INTERPRETATION TO SCIENCE: FOR A PHILOSOPHICAL HISTORY OF POLITICAL KNOWLEDGE IN BRAZIL}

The essay deals with a dissimilarity, current in the field of Brazilian political reflection, between two different perspectives: one presented as scientifically founded, the other defined as marked by interpretation. Such a contrast leads to a denial that the interpretive branch - dubbed as "Brazilian political 
thought" or as "Brazilian's interpretations" - may generate possible cognitive effects. Moreover, the authors that belong to this variant are regularly assumed by analysts more as objects to be explained than as cognitive inspiration. On the other hand, the aim to accomplish objective and exact knowledge on political matters, as affirmed by the "scientific" variant from the 1980's on, is determined by the desire to be free from the inherent limits and predicaments of interpretive efforts. The process is affected by an ongoing transfiguration of the object of political reflection and of the whole field of political knowledge altogether, supposed to be marked by strong uniqueness. The affirmation of such a singularity leads to a continuous effort of distinction towards the traditional procedures and assumptions of the field of humanities and social sciences.

Keywords: Transfiguration; Autonomy; Distinction; Political science; Brazilian's interpretations.

\section{TELENOVELAS E INTERPRETAÇÕES DO BRASIL}

\section{ESTHER HAMBURGER}

Ao longo dos últimos quarenta anos, as telenovelas - seriados comerciais exibidos seis vezes por semana em horário nobre, feitos para um público imaginado como feminino, mas assistidos por um público composto, em sua fase mais popular, em $40 \%$ por homens - se tornaram espaço privilegiado de interpretação do Brasil. Uma complexa rede de relações envolve a agenda militar autoritária nacionalista e desenvolvimentista; a agenda de anunciantes, homens da indústria e do comércio; e o talento de escritores, atores e diretores de esquerda (também nacional e desenvolvimentista) com repertório e conhecimento de cinema e teatro. Feita ao mesmo tempo em que vai ao ar, a novela captou e expressou ao menos três interpretações de um país que 